\title{
The dropout rate and associated factors of the continuum of maternal health care services before and during Covid-19 Pandemic among women who gave birth in the last two years in Addis Ababa, Ethiopia, 2021. A comparative cross-sectional study design
}

Dawit Zenamarkos Desta ( $\nabla$ dawit.zemark@gmail.com )

University of Gondar

Adane Kebede

University of Gondar

Mehari Woldemariam Merid

University of Gondar

Wubshet Debebe Negash

University of Gondar

Desale Bihonegn Asmamaw

University of Gondar

Research Article

Keywords: Continuum of care, dropout, COVID-19, Ethiopia

Posted Date: November 9th, 2021

DOI: https://doi.org/10.21203/rs.3.rs-1030571/v1

License: (a) This work is licensed under a Creative Commons Attribution 4.0 International License.

Read Full License 


\section{Abstract \\ Background}

A continuum of maternal health care is the continuity of care during pregnancy, delivery, and post-delivery period. However, the dropout rate of the continuum care and factors associated with it during the COVID19 pandemic were not well documented in the study setting. Hence, this study was used to assess the dropout rate and associated factors of the continuum of care before and during the COVID-19 pandemic.

\section{Methods}

A community-based comparative cross-sectional study was conducted among 630 women who gave birth in the last two years in Addis Ababa. An interviewer-administered questionnaires were used to collect the data. The Epi data version 4.6 and STATA version 14 statistical Softwares were used for data entry and analysis, respectively. Binary logistic regression model was used to identify associated factors of the dropout rate of a continuum of care.

\section{Result}

The dropout rate of the continuum of maternal healthcare was $58.39 \%$ (95\% Cl: $52.56-64.00)$ and $73.24 \%$ (95\% Cl: 67.91-77.98) before and during the covid-19 pandemic respectively. Women who had no information about PNC (AOR $=1.88,95 \% \mathrm{Cl}: 1.01-3.50)$, not received appropriate care (AOR $=3.92,95 \% \mathrm{Cl}$ : 1.84-8.37), no information about maternal health care ( $\mathrm{AOR}=2.57,95 \% \mathrm{Cl}: 1.28-5.16)$, birth preparedness and complication readiness (AOR $=0.47,95 \% \mathrm{Cl}: 0.26-0.86)$, and had history of pregnancy-related complications (AOR=2.07, 95\% Cl: 1.17-3.68), were dropped out from continuum of care during the covid19 pandemic. whereas, unplanned pregnancy (AOR=3.35, 95\% Cl: $1.60-7.04)$, not know postpartum danger signs ( $A O R=1.79,95 \% \mathrm{Cl}: 1.03-3.12)$, and no information about maternal health care $(A O R=1.85$, $95 \% \mathrm{Cl}: 1.06-3.23)$ were dropped out from continuum of care before covid-19 pandemic.

\section{Conclusion}

This study underscores nearly three fourth and more than half of women during and before the covid-19 pandemic dropped out from the continuum of care, respectively. Information about maternal health care, birth preparedness and complication readiness, information about PNC, and knowing postpartum danger signs were significantly associated with the dropout rate of the continuum of care. Thus, adapting policy that supports service delivery modification during such pandemic, promoting birth preparedness and complication readiness is very crucial.

\section{Background}


Continuum of maternal health care, refers the continuity of care throughout the pregnancy, childbirth, and post-delivery period, it is very important to the health of the women, newborn, and the community as well. Maintaining the continuum of care could help to improve service quality by avoiding fragmentation of service at the point of transition from one service or professional to another [1, 2].

Keeping a continuum of maternal healthcare services pathway is an important strategy to improve maternal and child health. To make the world healthy and comfortable for its citizen keeping the health of women may be important quoin [3].The majority of maternal death occurs due to inadequacy of care. The deaths may prevent with access to ANC and delivery with the help of a skilled birth attendant or receipt of postnatal care within 48 hours after delivery [4].

Continuum of maternal health care (COMHC) is a very salient strategy to boost maternal, newborn, and child health. It is also important to deliver quality maternal health care services by building a lifelong integrated, comprehensive, and responsive health system $[3,5,6]$. Therefore, the breakdown of the continuum of maternal healthcare may lead to more maternal and child morbidity and mortality [7].

Despite a $35 \%$ decline in maternal mortality recorded since 2000, there were an estimated 295,000 maternal deaths globally in 2017. This creates an aggregate rate of maternal mortality of 211 maternal deaths per 100000 live births. Developing nations such as in Africa contribute the majority (99\%) of global maternal mortality. Tragically, countries in sub-Saharan Africa account for $66 \%$ of maternal deaths globally. In this sub-region, the maternal mortality rate was estimated at 542 maternal deaths per 100,000 live births, with a lifetime probability of maternal death of 1 in 37 . despite this, there is a significant disparity in maternal mortality rates, from 7 in Australia and New Zealand to 415 maternal deaths per 100 000 live births in the least developed countries, $[8,9]$.

In Ethiopia, the maternal mortality rate is 401 deaths per 100,000 live births [10]. According to EDHS 2016, Thirty-two percent of women had at least four ANC visits. Among women who receive more than four ANC visits only $56 \%$ of the women delivered at the health institution. Out of these only, $58 \%$ give birth with the help of a skilled birth attendant, and among women who delivered in a health facility, only $42 \%$ get postnatal care [11].

Despite, the tremendous achievement in improving maternal health care service utilization, the low maternal health care continuum remains a notable hitch in Ethiopia. For instance, studies conducted elsewhere in Ethiopia before the COVID-19 pandemic revealed a great disparity in the dropout of COMHC from $53 \%$ in northeast Ethiopia to $90.3 \%$ in Arbaminch Zuria district [12-15]. Poor quality of care, previous negative experiences with health facilities, low awareness of the advantages of skilled attendance at delivery, having a little role in decisions making and having economic curtailments during referral contribute to the low level of service utilization. [11, 16, 17].

To impact all these challenges Maternal health becomes one of the targets that sustainable development goals give emphasis. Sustainable development goals (SDGs) plan to reduce the maternal mortality rate to $<70$ per 100,000 live births by the year $2030[9,18,19]$. Comparably, maternal and child health (MCHs) 
have been and are too major priority areas in Ethiopia. There is an ambitious plan to minimize MMR from 401 in 2020 to 140 per 100,000 live births in 2029. There is also a plan to double the proportion of pregnant women with four and more ANC visits, delivery with skilled birth attendants (SBA), and early Postnatal care (PNC) coverage from $43 \%$ in 2020 to $95 \%$ in $2029,50 \%$ in 2020 to $95 \%$ in $2029,34 \%$ in 2020 to $95 \%$ in 2029 respectively $[10,11]$.

Despite this, COVID-19 pandemic has posed big challenges to the maternal health care services. And it is expected that the maternal health care continuum has been highly affected by the COVID-19 pandemic [20-22]. However, the dropout rate and associated factors of the continuum of maternal healthcare during the COVID-19 pandemic were not well documented. Thus, this study aimed to determine the dropout rate and associated factors of the continuum of maternal health care services before and during COVID-19 pandemic among women who gave birth in the last two years in Addis Ababa. Ethiopia.

\section{Methods}

\section{Study design and period}

A community-based comparative cross-sectional study design was conducted among women who gave birth in the last two years in Addis Ababa. The dropout rate of the continuum of maternal health care one year before (from march 13,2019 to march 12,2020) the registration of the first covid 19 cases in Ethiopia and one year during (from March 13, 2020, to March 12, 2021) the covid 19 pandemic was compared. The data was collected from April to May 2021.

\section{Study setting}

The study was conducted in Addis Ababa, the capital of Ethiopia, city administration. Based on 2017 projection, the city has a population of $3,435,028$ inhabitants. Out of this $1,809,577$ were female, of this around $34.6 \%$ were reproductive age women [23]. The city has 11 sub-cities and 116 Districts (Woreda). It has 13 hospitals and 98 health centers within its jurisdiction. There were 15566 health professionals: including 2,352 doctors, 7,496 nurses, 1,426 midwives, 1,520 pharmacists, 1,483 medical lab, 1,289 health officers, and 1144 Health Extension workers. This makes the health professional to population ratio 1: 237 [24].

\section{Population}

All women who gave birth in the last two years and were booked for ANC in Addis Ababa before the time of data collection were a source population. On the other hand, all women who gave birth in the last two years and were booked for ANC in the selected sub-cities of Addis Ababa were study population. Women who gave their most recent birth in the last two years, who had booked for ANC, and who were at two days or more during the time of data collection were included. However, Women who lived in the study area for less than six months at the period of data collection, end up their pregnancy with abortion, within two days of delivery, and who became pregnant after September 2020 were excluded from the study. 


\section{Sample size}

The sample size was calculated using double population proportion formula using epi info 7 and an assumption of $95 \%$ confidence level, $80 \%$ power (probability of getting a significant result), $5 \%$ Marginal error (d), P1 (proportion of the dropout rate of the COMHC before COVID-19 pandemic) 53\% from research done in Motta town and Hulet Eji Enese district, Ethiopia [15], And P2 (proportion of dropout rate of the COMHC during COVID-19 pandemic) $=38 \%$, Since there was no previous study conducted that relates dropout rate of the continuum of maternal health care and COVID-19 a $15 \%$ difference [25] was assumed between dropout from COMHC before COVID-19 pandemic and dropout from COMHC during the COVID19 pandemic. Then $10 \%$ non-response rate and a 1.5 design effect were added. Hence, sample size $\mathrm{n}_{1}$ (dropout before COVID-19) $=223$ and $n_{2}$ (dropout during COVID-19) $=159$. Hence, a total of 630 samples were included in the study. And 1:1 ratio was used to select participants from women booked for ANC service before and during the covid-19 pandemic in Ethiopia.

\section{Sampling procedures}

A multistage sampling technique was employed to recruit the 630 participants. Firstly, the Addis Ababa city administration, which has 11 sub-cities, was selected as a study area. Then 4 of the 11 sub-cities, namely Addis Ketema, Nifassilk Lafto, Kirkos, and Lideta sub-cities, were selected using a simple random sampling technique, then 10 districts (weredas) out of 43 weredas in the four sub-citie were selected using simple random sampling. After this, a participant from each wereda was allocated proportionally based on the number of the women who gave birth in the last two years before the data collection period (information obtained from the District Health Information System) in each wereda. Finally, the study participants were selected using simple random sampling techniques, from the antenatal care [20] registration book from health centers in the respective districts. Then having the name and house number or phone number the interview of the women was conducted home to home (figure 1).

\section{Variable and measurements}

Dropout from $\mathrm{COMHC}$ was the dependent variable. Whereas, Socio-demographic factors (age, sex, marital status, educational status, family size, occupation and residence), Fear of covid-19, healthcare accessibility related factors, Knowledge and Attitude towards covid-19 related factors and Obstetric factors were the independent variables.

Complete COMHC: - A woman was said to have a complete continuum of maternal health care if she has attained 4 and above ANC visits, childbirth in a health institution and receives PNC service within 48 hours after delivery by a trained health professional $[26,27]$. The dropout rate of COMHC: dropout from COMHC was considered when women have not 4 and above ANC visits, delivered out of health facility, or not having at least one postnatal care within 48 hours after delivery [26]. Birth preparedness and complication readiness: six questions were used to measure birth preparedness and complication 
readiness. The elements of BPCR considered in this study were having identified a place of delivery, identified skilled birth attendants, saved money before delivery, identified means of emergency transport, recognized signs of labor, and identify supplies needed during labor. And those women who reported that they have applied five or more of BPCR were considered as having birth preparedness and complication readiness [13].Women autonomy: A woman was said to have autonomous decision-making power in seeking maternal health services if she alone or with her husband (jointly) decided on seeking maternal health services $[14,28]$.Knowledge: the questionnaire assessing knowledge has 9 items. And was classified as 'correct' and 'incorrect" and coded as 1 for correct and 0 for incorrect responses. Those respondents who respond above the mean score (10) were considered as having good knowledge, whereas, those below the mean value were labeled as poor knowledge [29]. Attitude: eight questions were used to assess attitude towards the covid-19 pandemic, the scores were based on 5-point Likert scales, ranging from strongly disagree to strongly agree. And all attitude scores were computed. those respondents who respond above the mean (27) score were considered as having a positive attitude, whereas, below the mean value was labeled as a negative attitude [29]. Fear: seven items were used to assess fear. The scores were based on 5-point Likert scales, ranged from strongly disagree to strongly agree. Those Participants who respond above the mean score (20) were considered as fearful towards COVID-19 [30].

\section{Data collection tools and procedures}

Data were collected through face-to-face interviews using pretested, structured questionnaires. The data collection tool was adapted from different literatures [13,31,32]. The questioner was developed in English first, then translated to Amharic, and retranslated back to the English language to check its consistency. The questionnaire was compressed into sub-section like socio-demographic characteristics, obstetric characteristics, fear towards covid-19; maternal knowledge and attitude toward Covid_19, and accessibility of health care service. Data collectors were approached by introducing themselves and interviewing the selected respondent after informed consent was obtained.

\section{Data quality assurance}

Three health officers have participated in the data collection process. The data collectors were given a one-day training regarding the objective, the data collection tools, and the data collection technique to make them familiar with the study. The questionnaires were pretested on $5 \%$ of the total sample size before the actual data collection was started. Daily evaluation of the data completeness, accuracy, and consistency as well as a corrective discussion was undertaken with the data collectors every day. Finally, all the collected data was checked by the investigator for its completeness and consistency during the data management, storage, and analysis. And Epi data version 4.6 was used to minimize data entry errors. 


\section{Data processing and analysis}

Each questionnaire was coded and entered into Epi data version 4.6 and was exported to STATA virsion14 statistical software. Before analysis, data were cleaned using frequency; listing, and sorting to identify any missed values, and then corrections were made by revising the original coded questionnaire. First descriptive analysis was carried out to examine the distribution of each variable. The Shapiro-Wilk test was employed to see the normal distribution of the variables and to identify which summary measures were appropriate to use. The outcome variable was dichotomized as "have ANC" and "have not ANC", "institutional delivery" and "delivery out of health institution"," have PNC" and "Have not PNC". As such, having ANC service, institutional delivery, and PNC service was labeled as " 1 " and " 0 " for having no ANC, delivery out of health institution, Have not PNC, respectively. Then, Tables, graphs, and texts were used to present the finding of the study. Also, the chi-square test was applied to find out the association between dependent and categorical independent variables. Then the binary logistic regression model was employed to identify factors significantly associated with the dropout rate of the continuum of maternal healthcare. Odds ratio (OR) with $95 \% \mathrm{Cl}$ was estimated to show the strength of association. Those variables which have a $p$-value $<0.2$ in the bivariable analysis were entered into multivariable logistic regression. And a P-value of $<0.05$ in the multivariable logistic regression analysis was used to identify associated factors of the dropout rate of the continuum of maternal healthcare service. Multicollinearity among independent variables was checked using Variance inflation factors (VIF). Therefore, the mean VIF for factors associated with the dropout rate of the continuum of maternal health care service during the covid-19 pandemic was 1.05. comparably, 1.08 was the mean VIF for factors associated with the dropout rate of the continuum of maternal healthcare service among women booked for ANC before the covid-19 pandemic. Since the VIF was less than 10 there was no multicollinearity in our study. In addition to this, Model fitness was checked using the Hosmer-Lemeshow test, and p-value $>0.05$ was considered adequate. As a result, the value for the model fitness test was 0.50 for factors associated with the dropout of the continuum of maternal healthcare service during the pandemic. Likewise, 0.86 was the value of model fitness for factors associated with the dropout rate of the continuum of maternal healthcare service among women booked for ANC service before the covid-19 pandemic.

\section{Results}

\section{Socio-demographic characteristics of the participants}

In this study, a total of 585 women were interviewed with a response rate of $92.9 \%$ of which: 286 with a response rate of $90.8 \%$ were women who booked for ANC service before the covid-19 and the 299 with a response rate of $94.9 \%$ were women who book for ANC service during covid-19.

The mean age \pm standard deviation (SD) of women booked for ANC during and before the covid-19 pandemic was $27.78( \pm 4.86)$ and $28.45( \pm 5.24)$ years respectively. Three of five $(60.49 \%$ and $60.54 \%$ of women booked for ANC before and during covid-19) women were in the age group of 25-34 years. 
Regarding the educational status, $38.46 \%$ and $38.80 \%$ of women booked for ANC before and during the covid-19 have completed their primary school. Whereas, significant proportion of women, $22.73 \%$ and $28.09 \%$ of women booked for ANC before and during the covid-19, attained college and above educational level.

The majority of the respondent, $87.41 \%$ of women booked before and $94.31 \%$ of women booked during the covid-19 were married. And the majority, $63.99 \%$ of women booked before, and $69.57 \%$ of women booked for ANC service during the covid-19 case were housewives (Table 1 ).

Table 1:Socio-Demographic Characteristics of women who gave birth in the past two years before and during the COVID-19 pandemic in Addis Ababa,2021 $(n=585)$ 
Variable

Age

Women Occupation

Women educational

tons

Orthodox

Muslim

Protestant

Catholic

Others *

status

$\leq$ primary education

secondary education

college and above

Housewife

Self-employee

Daily worker

Government employee

Private employee

Marital status

Student

Frequency (\%)

$\begin{array}{ll}\text { Before covid- } & \text { During } \\ \begin{array}{ll}19(\mathrm{n}=286) & \text { covid- } \\ & 19(\mathrm{n}=299)\end{array}\end{array}$

69 (24.13) 79(26.42)

$\begin{array}{ll}173(60.49) & 181(60.54) \\ 44(15.38) & 39(13.04)\end{array}$

145(50.70) 179(59.87)

$69(24.13) \quad$ 62(20.74)

57(19.93) 49(16.39)

10(3.50) $\quad 6(2.01)$

$5(1.75)$

$3(1.00)$

$\begin{array}{ll}143(50.00) & 147(49.16) \\ 78(27.27) & 84(28.09) \\ 65(22.73) & 68(22.74)\end{array}$

183(63.99) 208(69.57)

$37(12.94) \quad 28(9.36)$

\begin{tabular}{cc}
$8(2.80)$ & $7(2.34)$ \\
\hline $26(9.09)$ & $30(10.03)$
\end{tabular}

$24(8.39) \quad 23(7.69)$

Single

Divorced

Widowed

8(2.80) 3(1.00)

250(87.41)

282 (94.31)

21(7.34)

10(3.34)

12(4.20)

6 (2.01)

$1(0.35)$

$0(0)$ 


\begin{tabular}{|c|c|c|c|c|}
\hline & \multicolumn{2}{|l|}{ separated } & $2(0.70)$ & $1(0.33)$ \\
\hline \multirow[t]{4}{*}{ Husband education status } & \multicolumn{2}{|c|}{ no formal education } & $24(9.52)$ & 26(9.19) \\
\hline & \multicolumn{2}{|c|}{ primary education } & $86(34.13)$ & $87(30.74)$ \\
\hline & \multicolumn{2}{|c|}{ secondary education (9-12) } & $70(27.78)$ & $105(37.10)$ \\
\hline & \multicolumn{2}{|c|}{ college and above } & $72(28.57)$ & $65(22.97)$ \\
\hline \multirow[t]{5}{*}{ Husband occupation } & \multicolumn{2}{|c|}{ self-employee } & $106(42.06)$ & $125(44.17)$ \\
\hline & \multicolumn{2}{|c|}{ Government Employed } & $35(13.89)$ & $46(16.25)$ \\
\hline & \multicolumn{2}{|c|}{ Private employee } & $66(26.19)$ & $55(19.43)$ \\
\hline & \multicolumn{2}{|c|}{ Daily worker } & $45(17.86)$ & $51(18.02)$ \\
\hline & \multicolumn{2}{|l|}{ Other ${ }^{*}$} & $0(0)$ & $6(2.12)$ \\
\hline \multirow[t]{4}{*}{ Family monthly income (ETB) } & \multicolumn{2}{|c|}{ below and equal 500} & $14(4.90)$ & $6(2.01)$ \\
\hline & \multicolumn{2}{|l|}{$501-1500$} & $17(5.94)$ & $26(8.70)$ \\
\hline & \multicolumn{2}{|l|}{$1501-2500$} & $27(9.44)$ & $26(8.70)$ \\
\hline & \multicolumn{2}{|c|}{2501 and above } & $228(79.72)$ & $241(80.60)$ \\
\hline \multirow{2}{*}{$\begin{array}{l}\text { Information About maternal } \\
\text { health care }\end{array}$} & \multicolumn{2}{|l|}{ Yes } & $194(67.83)$ & $210(70.23)$ \\
\hline & \multicolumn{2}{|l|}{ No } & $92(32.17)$ & $89(29.77)$ \\
\hline \multirow[t]{8}{*}{ Source of information } & \multirow[t]{2}{*}{ Radio / Tv } & Yes & $31(15.98)$ & $42(20.00)$ \\
\hline & & No & 163(84.02) & $168(80.00)$ \\
\hline & \multirow[t]{2}{*}{$\begin{array}{l}\text { Health } \\
\text { Professional }\end{array}$} & Yes & $166(85.57)$ & 181(86.19) \\
\hline & & No & $28(14.43)$ & $29(13.81)$ \\
\hline & \multirow[t]{2}{*}{ School } & Yes & $25(12.95)$ & $20(9.52)$ \\
\hline & & No & 169(87.05) & $190(90.48)$ \\
\hline & \multirow[t]{2}{*}{ Relative } & Yes & $4(2.06)$ & $3(1.43)$ \\
\hline & & No & 190(97.94) & 207(99.04) \\
\hline
\end{tabular}


Frequency to watch and hear the radio/ Television
Always

25(80.65)

$36(85.71)$

Once a week

2(6.45)

$1(2.38)$

More than once a week

$4(12.90)$

$5(11.90)$

*Jehovah witness, seven-day Adventist, ${ }^{* \star H a v e ~ n o ~ j o b, ~ l i v e s ~ o u t ~ o f ~ t h e ~ c o u n t r y ~}$

\section{Health service accessibility of the participants}

Furthermore, more than two-thirds $(81.12 \%$ and $84.28 \%$ of women booked for ANC service before and during the covid-19 pandemic) spends less than 30 minutes to reach the health facility respectively. And more than half,59.44 and 57.19 before and during the pandemic respectively, of the women booked for ANC service uses walking to go to the health facility. Comparably, $94.06 \%$ of women booked for ANC before, and $94.31 \%$ of women booked for ANC during the covid-19 pandemic use health centers to get ANC service. and $40.91 \%$ of the women booked for ANC before covid-19 and $43.14 \%$ of the women booked for ANC during covid-19 have more than three PNC visits during delivery (Table 2).

Table 2: Health service accessibility-related characteristics of women who gave birth in the past two years before and during the COVID-19 pandemic in Addis Ababa,2021 $(n=585)$ 


\begin{tabular}{|c|c|c|c|}
\hline & & \\
\hline & & $\begin{array}{l}\text { Before covid- } \\
19(n=286)\end{array}$ & $\begin{array}{l}\text { during covid-19 } \\
(\mathrm{n}=299)\end{array}$ \\
\hline \multirow[t]{2}{*}{ Women autonomy } & Not autonomous & $7(2.45)$ & 11(3.68) \\
\hline & Autonomous & $279(97.55)$ & 288(96.32) \\
\hline \multirow{2}{*}{$\begin{array}{l}\text { Distance from the health } \\
\text { facility (minute) }\end{array}$} & $<30$ minutes & 232(81.12) & $252(84.28)$ \\
\hline & $\geq 30$ minutes & $54(18.88)$ & $47(15.72)$ \\
\hline \multirow{2}{*}{$\begin{array}{l}\text { Means of transportation to } \\
\text { health facilities }\end{array}$} & by car & $116(40.56)$ & $128(42.81)$ \\
\hline & Walking on foot & 170(59.44) & 171(57.19) \\
\hline \multirow[t]{5}{*}{ Place of ANC visit } & Gov't hospital & $4(1.40)$ & $4(1.34)$ \\
\hline & health center & $269(94.06$ & 282(94.31) \\
\hline & Private hospital & $7(2.45)$ & $10(3.34)$ \\
\hline & Private clinic & $3(1.05)$ & $1(0.33)$ \\
\hline & Marie stops & $3(1.05)$ & $2(0.67)$ \\
\hline \multirow[t]{2}{*}{ place of delivery } & health institution & $282(98.60)$ & $290(96.99)$ \\
\hline & $\begin{array}{l}\text { out of health } \\
\text { institution }\end{array}$ & $4(1.40)$ & $9(3.01)$ \\
\hline \multirow[t]{4}{*}{$\begin{array}{l}\text { Reason for not delivering } \\
\text { in health facility }\end{array}$} & $\begin{array}{l}\text { Shifting of human } \\
\text { resource to covid-19 }\end{array}$ & 0 & 1(11.11) \\
\hline & $\begin{array}{l}\text { Shifting of medical } \\
\text { supplies to covid-19 }\end{array}$ & 0 & $1(11.11)$ \\
\hline & $\begin{array}{l}\text { Closures of health } \\
\text { facilities due to covid- } \\
19\end{array}$ & 0 & $3(33.33)$ \\
\hline & Other* & 0 & $4(44.44)$ \\
\hline \multirow{2}{*}{$\begin{array}{l}\text { Start PNC service within } 48 \\
\text { hr. after delivery }\end{array}$} & Yes & $160(55.94)$ & $140(46.82)$ \\
\hline & No & $126(44.06)$ & 159(53.18) \\
\hline \multirow[t]{3}{*}{ Number of PNC visit } & 0 & $70(24.48)$ & $56(18.73)$ \\
\hline & $1-2$ & $99(34.62)$ & 114(38.13) \\
\hline & 3 and above & 117(40.91) & $129(43.14)$ \\
\hline $\begin{array}{l}\text { Reason for missing PNC } \\
\text { service }\end{array}$ & $\begin{array}{l}\text { Shifting human } \\
\text { resources to covid-19 }\end{array}$ & 0 & $4(7.14)$ \\
\hline
\end{tabular}


prevention

Shifting budget to
covid-19 prevention

Shifting medical

supplies to covid-19

prevention

lockdown

Closures of health

facilities due to covid-

19
0

$5(2.31)$

197(91.20)

$8(3.70)$

6(2.78)
2(3.57)

17(30.36)

19(33.93)

10(17.86)

Government hospital

health center

Private hospital

Private clinic

Every 15 minutes

Every 30 Minute

Every one hour

two hour and above

Shortage of health care providers

Reasons for the less frequent visit by health care providers
Frequency of visit by health care provider immediately after birth
10(4.12)

224(92.18)

$9(3.70)$

Place of PNC service

\section{care providers}

Time spent in health

facility after delivery

Health care providers were busy

22(57.89) (1)

\begin{tabular}{llcl} 
& Health care providers negligence & $10(26.32)$ & $24(28.57)$ \\
\cline { 2 - 4 } & Other & & \\
& $\geq 24$ Hour & $5(1.75)$ & $5(5.95)$ \\
\hline $\begin{array}{l}\text { Time spent in health } \\
\text { facility after delivery }\end{array}$ & $<24$ Hour & $177(62.32)$ & 156 \\
& Shortage of beds & $107(37.68)$ & $137(46.76)$ \\
\hline $\begin{array}{l}\text { Reasons for staying less } \\
\text { than 24 hours }\end{array}$ & Shortage of health care providers & $3(2.80)$ & $62(45.26)$ \\
\cline { 2 - 4 } & Others & $52(48.60)$ & $6(4.38)$ \\
\hline Receive appropriate care & Yes & $259(90.56)$ & 218(50.36) \\
\hline
\end{tabular}


Reasons for not getting appropriate care
Fear of covid-19 health care providers

Shortage of medical supplies

Shortage of health care providers

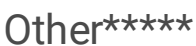

0

42(51.85)

21(25.93)
12(44.44)

8(29.63)
18(22.22)

*The labor was emergent** I did not think it was necessary, I was lost my child, they did not give me an appointment, to do what? already I give birth safely. $\star \star \star$ there was covid 19, I was healthy, they fear covid $19, \star \star \star \star$ I was healthy, there was covid-19, financial problem, referral to hospital, stillbirth, $\star \star \star \star \star$ they sit and talk, discrimination, negligence, they give me wrong medication and they were busy with social media.

\section{Obstetrics characteristics of the participants}

More than three-fourth (81.82\%) of women booked for ANC service before and $86.29 \%$ of the women booked for ANC service during the covid-19 pandemic were planned/wanted to deliver their child.

Additionally, $80.07 \%$ of the women who received maternal health care service before covid- 19 and $72.58 \%$ of the women who received maternal health care service during the covid-19 pandemic starts their first ANC service before the 16 weeks of pregnancy. And most,72.03\% and $63.55 \%$ of the women booked before and during the covid-19 pandemic respectively were informed when to return for PNC service. The majority of the women, $61.89 \%$ of women booked for ANC before, and $72.58 \%$ of women booked for ANC during the covid-19 pandemic, were not prepared to deliver their child (Table 3).

Table 3:Obstetrics characteristics of women who gave birth in the past two years before and during the COVID-19 pandemic in Addis Ababa,2021 
Variable Category

Frequency (\%)

Before covid-19

During

covid-19

Pre-pregnancy

utilization of

contraception

Yes

202(70.63)

190(63.55)

No

84(29.37)

109

(36.45)

Type of

Pills

42(20.79)

49(25.79)

contraception

Implants

67(33.17)

47(24.74)

IUCD

7(3.47)

11(5.79)

Depo

86(42.57)

83(43.68)

Total number of pregnancies

1

103(36.01)

128

(42.81)

(Gravidity)

Total number live of

births (Parity)

2-3 and above

153(53.50)

145(48.49)

30(10.49)

26(8.70)

0

2(0.70)

5(1.67)

1

110(38.46)

129(43.14)

2-3

151(52.80)

141

(47.16)

4 and above

23(8.04)

24 (8.03)

Number of children

0

2(0.70)

5 (1.67)

currently alive

1

110(38.46)

129

(43.14)

2-4

173(60.49)

141(47.16)

5 and above

1 (0.35)

24(8.03)

Had

Yes

234(81.82)

258

Planned/wanted

current pregnancy

No

$52(18.18)$

(86.29)

41(13.71)

Time to be pregnant I want to stay

40(76.92)

35(85.37)

I did not want

12(23.08)

$6(14.63)$

Gestational age at first ANC visit

(weeks.)

at and before 16 weeks

229(80.07)

217

(72.58)

during 16 weeks

57(19.93)

82(27.42) 
$<4$ times $\quad$ 67(23.43)

Number of ANC visit $\geq 4$ times $219(76.57)$ $180(60.20)$

Reason for missing ANC visit

Shifting of medical supplies to covid-

0

$3(2.52)$

Cancellation of regular ANC

0

46(38.66) appointment

Lockdown

Others*

SVD

Mode of delivery

CS

Instrumental

History of pregnancy-related complications

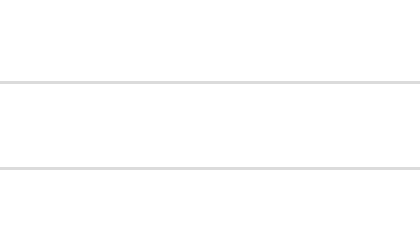

0

0

228(79.72)

54(18.88) 4(1.40)
44(36.97)

26(21.85)

223(74.58)

69(23.08)

7(2.34)

Yes $\quad 102$

(35.66)

184(64.34) 195(65.22)

No

Complications

Obstetric bleeding (APH/PPH)

pregnancy related Diabetes

Knowing postpartum danger sign

Yes

Vaginal bleeding
Abortion

still birth

Birth by operation

Preeclampsia/Eclampsia

$10(9.80) \quad 8(7.69)$

No

113(63.84) 103(61.68)

$25(24.51) \quad 24(23.08)$

$7(6.86)$

2(1.96)

3(2.88)

$51(50.00) \quad 57(54.81)$

$7(6.86)$

$3(2.88)$

167(55.85)

177(61.89)

109(38.11)

132

(44.15)

Increased body temp (fever)

25(14.12)

27(16.17)

Offensive vaginal Discharge

$39(22.03)$

33(19.76) 


\begin{tabular}{llrl} 
& Other's** & & $4(2.40)$ \\
\hline Information about PNC checkup & Yes & $206(72.03)$ & $\begin{array}{l}190 \\
(63.55)\end{array}$ \\
\cline { 2 - 4 } & No & $80(27.97)$ & $109(36.45)$ \\
\hline $\begin{array}{l}\text { Birth preparedness and } \\
\text { complication readiness }\end{array}$ & Not well prepared & $177(61.89)$ & $217(72.58)$ \\
\cline { 2 - 4 } & Well prepared & $109(38.11)$ & $82(27.42)$
\end{tabular}

* I was afraid of covid 19, closure of health facility due to covid-19, I did not know I was pregnant, I was busy at work ** body tremor, foot swelling, infection, swelling of the foot.

\section{Knowledge, Attitude, and Fear about COVID-19}

Among women booked for ANC service during the covid-19 pandemic, more than half (51.84\%) of the participants did not know about the covid-19 pandemic. And more than half (52.17\%) of the participants have a favorable attitude towards the covid- 19 pandemic. additionally, more than half $(57.53 \%)$ of the women booked for ANC were fearful (Table 4).

Table 4:COVID-19 related Knowledge, Attitude and Fear of women who gave birth in the past two years before and during the COVID-19 pandemic in Addis Ababa,2021

\begin{tabular}{llll} 
Variable & Category & Frequency $(\mathrm{n}=299)$ & Percentage \\
\hline Knowledge & Un-knowledgeable & 155 & 51.84 \\
\cline { 2 - 4 } & Knowledgeable & 144 & 48.16 \\
\hline \multirow{2}{*}{ Attitude } & Un-favorable & 143 & 47.83 \\
\cline { 2 - 4 } & favorable & 156 & 52.17 \\
\hline \multirow{2}{*}{ Fear } & not fearful & 127 & 42.47 \\
\cline { 2 - 4 } & fearful & 172 & 57.53 \\
\hline
\end{tabular}

\section{The dropout rate of continuum maternal healthcare services}

Among women booked for ANC before covid-19 58.39\% (95\% Cl: 52.56-64.00) dropped out from the continuum of maternal healthcare. but $41.61 \%(95 \% \mathrm{Cl}$ : $35.99-47.44)$ completed their recommended maternal health care service. Likewise, among women booked for ANC service during the covid 19 
pandemics $73.24 \%$ (95\% Cl: 67.91-77.98) dropped out from the continuum of maternal healthcare. However, $26.76 \%$ (22.01-32.09) completed their recommended maternal health care service (Figure 2).

\section{Factors associated with the dropout rate of the COMHC}

\section{Factors Associated with the dropout rate of the COMHC before the COVID-19}

Bivariable and multivariable logistic regression analyses were fitted to identify factors associated with the dropout rate of the continuum of maternal health care service. Hence, information about maternal health care services, means of transportation to health facilities, pre-pregnancy utilization of contraception, planned-ness/wanted-ness of current pregnancy, birth preparedness and complication readiness, knowing postpartum danger signs, and informed about PNC checkup was found variables with p-value $<0.2$ in bivariable logistic regression and candidate for multivariable logistic regression.

Likewise, planned-ness/wanted-ness of current pregnancy, knowing postpartum danger signs, and having information about maternal health care services were factors significantly associated with the dropout rate of the continuum of maternal health care service in the multivariable logistic regression.

Accordingly, women who had unwanted or unplanned pregnancies were 3 times ( $\mathrm{AOR}=3.35,95 \% \mathrm{Cl}$ : 1.60 7.04) more likely to discontinue from the continuum of maternal health care than those women who had planned or wanted pregnancy.

The odds of dropout from the continuum of maternal healthcare were 1.79 times (AOR=1.79,95\% Cl: 1.03 3.12) higher among women who did not know postpartum danger signs than their counterparts.

Simultaneously, the dropout rate of the continuum of maternal healthcare is almost two times (AOR= $1.85,95 \% \mathrm{Cl}$ : 1.06-3.23) higher among women who had no Information About maternal health care services than their counterparts (Table 5).

Table 5:Bivariable and Multivariable Logistic Regression Analyses of factors Associated with the dropout rate of the continuum of maternal health care service among women who gave birth before the COVID-19 pandemic in Addis Ababa,2021

${ }^{*}$ Continuum of maternal healthcare, ${ }^{* *}$ crude odds ratio, ${ }^{* \star *}$ adjusted odds ratio, ${ }^{* * \star *}$ significant at $\mathrm{P}<0.05$

\section{Factors Associated with the dropout rate of the COMHC during the COVID-19}

Information about maternal health care services, receive appropriate care, knowledge about covid-19, planned-ness/wanted-ness of current pregnancy, birth preparedness and complication readiness, knowing postpartum danger signs, information about PNC checkup, and History of pregnancy-related complications were variables which have P-value $<0.2$ on bivariable logistic regression.

Comparably, on multivariable logistic regression being informed about PNC checkups, women receiving 


\begin{tabular}{|c|c|c|c|c|c|}
\hline \multirow[t]{2}{*}{ Variable } & \multirow[t]{2}{*}{ Category } & \multicolumn{2}{|l|}{$\mathrm{COMHC}^{\star}$} & \multirow{2}{*}{$\begin{array}{l}\mathrm{COR}^{\star \star} \\
(95 \% \mathrm{Cl})\end{array}$} & \multirow{2}{*}{$\begin{array}{l}\mathrm{AOR} \star \star \star \\
(95 \% \mathrm{Cl})\end{array}$} \\
\hline & & complete & Dropout & & \\
\hline \multirow{2}{*}{$\begin{array}{l}\text { Informed About maternal health } \\
\text { care services }\end{array}$} & Yes & 92 & 102 & 1 & 1 \\
\hline & No & 27 & 65 & $\begin{array}{l}2.17(1.28- \\
3.69)\end{array}$ & $\begin{array}{l}1.85(1.06- \\
3.23) * \star \star *\end{array}$ \\
\hline \multirow{2}{*}{$\begin{array}{l}\text { Means of transportation to health } \\
\text { facilities }\end{array}$} & with car & 59 & 57 & 1 & 1 \\
\hline & Walking & 60 & 110 & $\begin{array}{l}1.90(1.17- \\
3.07)\end{array}$ & $\begin{array}{l}1.67(0.99- \\
2.80)\end{array}$ \\
\hline \multirow{2}{*}{$\begin{array}{l}\text { Pre-pregnancy } \\
\text { utilization of contraception }\end{array}$} & Yes & 90 & 112 & 1 & 1 \\
\hline & No & 29 & 55 & $\begin{array}{l}1.52(0.89- \\
2.59)\end{array}$ & $\begin{array}{l}1.33(0.75- \\
2.34)\end{array}$ \\
\hline \multirow{2}{*}{$\begin{array}{l}\text { Had planned/wanted current } \\
\text { pregnancy }\end{array}$} & Yes & 108 & 126 & 1 & 1 \\
\hline & No & 11 & 41 & $\begin{array}{l}3.19(1.57- \\
6.52)\end{array}$ & $\begin{array}{l}3.35(1.60- \\
7.04) * * *\end{array}$ \\
\hline \multirow[t]{2}{*}{$\begin{array}{l}\text { Birth preparedness and } \\
\text { complication readiness }\end{array}$} & $\begin{array}{l}\text { Not well } \\
\text { prepared }\end{array}$ & 65 & 112 & 1 & 1 \\
\hline & $\begin{array}{l}\text { Well } \\
\text { prepared }\end{array}$ & 54 & 55 & $\begin{array}{l}0.59(0.36- \\
0.96)\end{array}$ & $\begin{array}{l}0.87(0.51- \\
1.48)\end{array}$ \\
\hline \multirow[t]{2}{*}{ Knowing postpartum danger signs } & Yes & 85 & 92 & 1 & 1 \\
\hline & No & 34 & 75 & $\begin{array}{l}2.04(1.23- \\
3.36)\end{array}$ & $\begin{array}{l}1.79(1.03- \\
3.12) * \star \star *\end{array}$ \\
\hline \multirow[t]{2}{*}{ Informed about PNC checkup } & Yes & 92 & 114 & 1 & 1 \\
\hline & No & 27 & 53 & $\begin{array}{l}1.58(0.92- \\
2.71)\end{array}$ & $\begin{array}{l}1.26(0.69- \\
2.29)\end{array}$ \\
\hline
\end{tabular}

appropriate care, having information about maternal health care services, birth preparedness, and complication readiness, and experience of pregnancy-related complications were significantly associated with a dropout from the continuum of maternal Health care.

Women who had no a history of pregnancy-related complications had 2 times (AOR=2.07, 95\% Cl: 1.17 3.68) more chance to discontinue from the continuum of maternal health care service than their counterparts.

Likewise, the odds of drop out of the continuum of maternal health care is 2 times (AOR $=1.88,95 \% \mathrm{Cl}$ : 1.01-3.50) higher among women who had not been informed about PNC checkups than those who had been informed about PNC checkup. 
In addition to this, women who perceive they did not receive appropriate care had 4 times (AOR $=3.92$, $95 \% \mathrm{Cl}: 1.84-8.37)$ increased chance of dropout from the continuum of maternal health care than those who perceive they receive appropriate maternal healthcare service.

Similarly, women who had information about maternal health care services were 2.57 times $(A O R=2.57$, $95 \% \mathrm{Cl}: 1.28-5.16)$ more likely to discontinue the continuum of maternal health care than women who had not information about maternal health care services.

This study also shows that the likelihood of dropout from the continuum of maternal healthcare decreased by $53 \%$ (AOR $=0.47,95 \% \mathrm{Cl}: 0.26-0.86)$ among women well prepared for birth and complication than those women who did not have birth preparedness and complication readiness (Table 6).

Table 6: Bivariable and Multivariable Logistic Regression Analyses of factors Associated with the dropout rate of the continuum of maternal health care service among women who gave birth during the COVID-19 pandemic in Addis Ababa,2021 


\begin{tabular}{|c|c|c|c|c|}
\hline \multirow{2}{*}{ Variable } & \multirow[t]{2}{*}{ Category } & $\mathrm{COMHC}^{\star}$ & \multirow{2}{*}{$\begin{array}{l}\mathrm{COR}^{\star \star} \\
(95 \% \mathrm{Cl})\end{array}$} & \multirow{2}{*}{$\begin{array}{l}\text { AOR } R^{\star \star *} \\
(95 \% \mathrm{Cl})\end{array}$} \\
\hline & & Complete & & \\
\hline
\end{tabular}

\begin{tabular}{|c|c|c|c|c|c|}
\hline \multirow{2}{*}{$\begin{array}{l}\text { Informed About maternal } \\
\text { health care services }\end{array}$} & Yes & 67 & 143 & 1 & 1 \\
\hline & No & 13 & 76 & $\begin{array}{l}2.74(1.42- \\
5.28)\end{array}$ & $\begin{array}{l}2.57(1.28- \\
5.16) * \star \star \star\end{array}$ \\
\hline \multirow[t]{2}{*}{ Receive appropriate care } & yes & 70 & 148 & 1 & 1 \\
\hline & No & 10 & 71 & $\begin{array}{l}3.36(1.63- \\
6.90)\end{array}$ & $\begin{array}{l}3.92(1.84- \\
8.37) * * * *\end{array}$ \\
\hline \multirow[t]{2}{*}{ Knowledge about covid-19 } & $\begin{array}{l}\text { Un- } \\
\text { knowledgeable }\end{array}$ & 48 & 112 & 1 & 1 \\
\hline & Knowledgeable & 32 & 107 & $\begin{array}{l}1.43(0.85- \\
2.41)\end{array}$ & $\begin{array}{l}1.43(0.81- \\
2.51)\end{array}$ \\
\hline \multirow{2}{*}{$\begin{array}{l}\text { Planned/wanted current } \\
\text { pregnancy }\end{array}$} & Yes & 74 & 184 & 1 & 1 \\
\hline & No & 6 & 35 & $\begin{array}{l}2.35(0.95- \\
5.81)\end{array}$ & $\begin{array}{l}1.84 \\
(0.69- \\
4.95)\end{array}$ \\
\hline \multirow[t]{2}{*}{$\begin{array}{l}\text { Birth preparedness and } \\
\text { complication readiness }\end{array}$} & $\begin{array}{l}\text { Not well } \\
\text { prepared }\end{array}$ & 48 & 169 & 1 & 1 \\
\hline & Well prepared & 32 & 50 & $\begin{array}{l}0.44(0.26- \\
0.76)\end{array}$ & $\begin{array}{l}0.47(0.26- \\
0.86) * * * *\end{array}$ \\
\hline \multirow{2}{*}{$\begin{array}{l}\text { Knowing postpartum } \\
\text { danger sign }\end{array}$} & Yes & 51 & 116 & 1 & 1 \\
\hline & No & 29 & 103 & $\begin{array}{l}1.56(0.92- \\
2.65)\end{array}$ & $\begin{array}{l}1.13(0.63- \\
2.02)\end{array}$ \\
\hline \multirow{2}{*}{$\begin{array}{l}\text { Information about PNC } \\
\text { checkup }\end{array}$} & Yes & 60 & 130 & 1 & 1 \\
\hline & No & 20 & 89 & $\begin{array}{l}2.05(1.10- \\
3.64)\end{array}$ & $\begin{array}{l}1.88(1.01- \\
3.50) * \star \star *\end{array}$ \\
\hline \multirow{2}{*}{$\begin{array}{l}\text { History of pregnancy-related } \\
\text { complications }\end{array}$} & Yes & 36 & 68 & 1 & 1 \\
\hline & No & 44 & 151 & $\begin{array}{l}1.82(1.07- \\
3.07)\end{array}$ & $\begin{array}{l}2.07(1.17- \\
3.68) * \star \star \star\end{array}$ \\
\hline
\end{tabular}

*Continuum of maternal healthcare, ${ }^{* \star}$ crude odds ratio, ${ }^{* * \star}$ adjusted odds ratio, ${ }^{* * *}$ significant at $\mathrm{P}<0.05$

\section{Discussion}

This study was aimed to determine and compare the dropout rate of the continuum of maternal healthcare service before and during the covid-19 pandemic and associated factors of the dropout rate of the continuum of maternal healthcare service among women who gave birth in the last two years. 
The dropout rate of the continuum of maternal healthcare was $58.39 \%$ (95\% Cl: $52.56-64.00)$ and $73.24 \%$ (95\% Cl: 67.91-77.98) among women booked for ANC service before and during the covid-19 pandemic, respectively.

This result disclosed that the dropout rate of continuum maternal healthcare service among women booked for ANC service during the covid-19 pandemic exceeds the dropout rate from the continuum of maternal healthcare care service among women booked for ANC service before the covid-19 pandemic. The exceedance of dropout rate of the continuum of maternal healthcare during the covid-19 pandemic might be due to the big challenges that covid-19 posed on maternal healthcare service: fear of women contracting the virus and transmitting to their unborn child, women's fear of social seclusion after visiting health institution during the pandemic, closure of health facilities because of covid-19 (changed to covid19 quarantine centers), the lockdown, and cancellation of service might increase the dropout rate of the continuum of maternal health care during the pandemic [7, 33-38].

The dropout rate of the continuum of maternal health care both before and during the covid-19 pandemic is lower compared to other elsewhere studies in India 81\% [5], Ratanakiri, Cambodia 95\% [39], Lao PDR 93.2\% [40], Bangladesh 88\% [41], Ghana 92\% [42], Ethiopia 90.1\% [43], Northwest Ethiopia 78.4\%[27], west Gojjam zone, Ethiopia 87.9\%[12], Pakistan [44] and Gamo zone, Ethiopia 90.3\% [14]. The possible explanation of this discrepancy could be the variation in socio-demographic characteristics like the place of residence of the participant where most of the aforementioned studies incorporated rural inhabitants, Variation in the educational status of the participant. For instance, unlike in this study, most (68.2\%) of the participants in a study conducted in Ratanakiri, Cambodia was not able to read and write.

However, results from other studies were consistent with findings from before the covid-19 pandemic but lower from the during covid-19 pandemic Nepal 59\% [45], Enemay District, Ethiopia 55\% [46]. This disagreement might be due to the covid-19 pandemic and time gap.

On the other hand, our findings from both before and during the covid-19 pandemic were higher than studies done in Cambodia 40\% [47], Kaski District, Nepal 25\% [1], and Debre Markos town 32.2\% [48], Motta town, Ethiopia 53\% [15]. One possible explanation for the variation in the dropout rate could be socio-demographic variability like the educational status of the participants. Consequently, the majority of $(67.5 \%)$ women in Nepal attend secondary education whereas in this study below $28.09 \%$ of the participant from both before and during the covid-19 pandemic attained secondary education. Likewise, the disagreement with the study in Debre Markos may be due to the difference in operationalizing the dropout rate. Unlike this study, the study in Debre Markos considers dropout from the maternity continuum of care when a woman had at least one visit of ANC but didn't use skilled birth attendant (SBA) and/or postnatal care.

Among women booked for ANC service before the covid-19 pandemic, planned-ness/wanted-ness of current pregnancy, knowledge of postpartum danger signs, and information about maternal health care services were factors significantly associated with the dropout rate of the continuum of maternal health care service. 
Accordingly, women who had unwanted or unplanned pregnancies were 3 times more likely to discontinue from $\mathrm{COMHC}$ than those women who had planned or wanted pregnancy. This was in agreement with other studies $[14,41,49]$. The possible reason for this could be Such women may initially deny their pregnancies and fail to start their maternal health care service as early $[12,14,50]$. Likewise, the women who wanted and planned pregnancy could be in need to have healthy outcomes this could increase their maternal health care service utilization.

The odds of the dropout rate of the continuum of maternal healthcare service were 1.79 times higher for women who do not know postpartum danger signs than women who know postpartum danger signs. This is consistent with a study conducted in other places [51,52]. The possible explanation for this could be women who know postpartum complications could be motivated to have postpartum care [53].

Simultaneously, the dropout rate of the continuum of maternal healthcare is almost two times higher among women who had no Information About maternal health care services than their counterparts. This is in agreement with the study conducted in rural villages of Sindh, Pakistan [44]. The possible explanation for this might be women who have information had a better understanding of pregnancy, delivery, and postpartum complications. It may also increase the knowledge and attitude towards a continuum of maternal healthcare and this may motivate their attachment to maternity service utilization [54].

This study revealed that being informed about PNC checkups, not receiving appropriate care, information about maternal health care services, birth preparedness, and complication readiness, and experience of pregnancy-related complications have significantly associated with the dropout rate of COMHC during the covid-19 pandemic.

Women who had a history of pregnancy-related complications had 2 times more chances to discontinue from the continuum of maternal health care service than their counterparts. This is in line with other studies $[15,51,55,56]$. The possible explanation for this might be women who have a history of pregnancy-related complications may know the risks associated with pregnancy. It might also be due to the increased contact rate of women to health professionals.

Comparably, the odds of the dropout rate of the continuum of maternal health care were 2 times higher among women who had not been informed about PNC checkups than who had been informed about PNC checkups. This is highly supported by a study done in Kaski District, Nepal, South Ethiopia, and Tigray [1, $49,53,57]$. The possible explanation for this may be women who have been informed about PNC checkup may stress the necessity of a PNC visit plus might be reinforced positively to have a PNC visit.

In addition to this, women who perceive they did not receive appropriate care were 4 times increased chance of dropout from the continuum of maternal health care than those who perceive they receive appropriate maternal healthcare service. this is in line with other studies [38, 44]. The possible explanation for this could be women who did not satisfy with their previous level of maternity service may fail to pursue their maternity health care service during the covid-19 pandemic. 
Similarly, women who had Information About maternal health care services were 2.57 times more likely to discontinue from the continuum of maternal health care than women who had no information. This is in line with the study conducted in Pakistan [44]. The possible explanation for this might be the women who have information have a better understanding of pregnancy, delivery, and postpartum complications. It may also increase the knowledge and attitude towards a continuum of maternal healthcare. And this may motivate their attachment to maternity service utilization [54].

This study also shows that the likelihood of dropout from the continuum of maternal healthcare decreased by $53 \%$ among women well prepared for birth and complication than those women who did not have Birth preparedness and complication readiness. This finding is comparable with the result of other studies $[13,14]$. The possible explanation for this could be women well prepared for birth and complication have high institutional delivery care status $[56,58]$. And those who deliver in health institutions have a high PNC service utilization [52, 59-61].

\section{Limitation of the study}

Some limitation of this study was that the data were collected based on women's self-report. This might lead to recall bias and social desirability bias. Besides, the cross-sectional nature of the study does not display a causal relationship.

\section{Conclusion}

In this study, nearly three fourth of women during the covid-19 pandemic dropped out from the continuum of maternal health care service. Similarly, more than half of the women before the covid-19 pandemic dropped out from the continuum of maternal health care service. in Addis Ababa, Ethiopia

Among women booked for ANC service before the covid-19 pandemic in Ethiopia, wanted-ness/ plannedness of current pregnancy, knowing postpartum danger signs, and information About maternal health care service were factors associated with the dropout rate of the continuum of maternal healthcare service.

Comparably, information about PNC checkups, receive appropriate care, Information About maternal health care services, history of pregnancy-related complications, and birth preparedness and complication readiness were factors associated with the dropout rate of the continuum of maternal healthcare service during the covid-19 pandemic. It is important to draw policies to make service delivery modifications to alleviate the challenges of the covid-19 pandemic on maternal healthcare service utilization. Additionally, providing timely and detailed information about the continuum of maternal healthcare service and the pandemic is very mandatory to increase women's awareness about maternal healthcare services, to reduce unplanned pregnancy which is hindering factor for maternal healthcare service utilization. 


\section{Abbreviations}

ANC: Antenatal care; Cl: Confidence Interval; COC: Continuum of Care; COMHC: Continuum of Maternal Health Care; EDHS: Ethiopian Demographic and Health Survey; ETB: Ethiopian Birr; HCP: Health Care Providers; MCH: Maternal and Child Health; MMR: Maternal Mortality Rate; MNCH: Maternal Neonatal and Child Health; OR: Odds Ratio; PNC: Postnatal care; PPE: Personal Protective Equipment; SBA: Skilled Birth Attendants; SDGs: Sustainable Development Goals; VIF: Variance inflation factors; WHO: World Health Organization

\section{Declarations}

\section{Ethical consideration}

Ethical clearance was obtained from the Institute of public health, College of Medicine, and Health Science on behalf of the Institutional Review Board of the University of Gondar with Ref No IPH/1407/2013. Official letters of support were obtained from the University of Gondar, institute of public health, and was given to Addis Ababa public health research and emergency management directorate. Ethical clearance was obtained from Addis Ababa public health research and emergency management directorate with Ref No $\square / \square / \square / 10184 / 227$. Then the support letter obtained from Addis Ababa public health research and emergency management directorate was given to the selected sub-city health offices. And support letter was obtained from the sub-city health office and given to selected health centers.

After a brief explanation of the objectives and purpose of the study, oral informed consent was taken from each study participant and the oral informed consent was approved by Addis Ababa public health research and emergency management directorate. Participants have been informed that participation was voluntary and they have the right to stop their participation at any time. Study participants were also be informed that all data obtained from them will be kept confidential by using codes instead of any personal identifier

To keep confidentiality all collected data was coded and locked in a separate room before being entered into the computer and names were not included in the data collection format. After entering the computer, the data was locked with a password, and the data will not be disclosed to anyone other than the principal investigator. in addition, to prevent participants from covid-19 infection prevention measures such as facemask, alcohol, and recommended physical distance were taken under consideration during the data collection process. The research was conducted according to the Helsinki declarations

\section{Consent for publish}

Not applicable.

\section{Availability of data and materials}

Data will be available upon reasonable request from the corresponding author 


\section{Competing interest}

The authors declare that they have no competing interests.

\section{Funding}

No funding available

\section{Authors' contributions}

DZD conceived the idea of this study, develop the research proposal and performed research analysis. AK and MWM were advisors throughout the proposal and research writings. DZD, WDN and DBA were involved in the analysis, thesis writing and manuscript writ up. All authors read and approved the final manuscript.

\section{Acknowledgments}

Our thanks goes to University of Gondar for ethical approval. We would like also thanks to Addis Ababa public health research and emergency management directorate, all sub city and district Health offices, data collectors and the research participants.

\section{References}

1. Koirala U, Kaphle HP, Yadav RK: Study of Different Factors Associated with Completion of Continuum of Care for Maternal Health Services in Kaski District, Nepal. Asian Research Journal of Gynaecology and Obstetrics 2020:13-22.

2. Psaila K, Schmied V, Fowler C, Kruske S: Discontinuities between maternity and child and family health services: health professional's perceptions. BMC health services research 2014, 14(1):1-12.

3. Akashi $H$, Ishioka $M$, Hagiwara A, Akashi R, Osanai Y: Core factors promoting a continuum of care for maternal, newborn, and child health in Japan. Bioscience trends 2018, 12(1):1-6.

4. Maternal, Neonatal and Child Health [https://www.usaid.gov/ethiopia/global-health/maternal-andchild-health]

5. Usman M, Anand E, Siddiqui L, Unisa S: Continuum of maternal health care services and its impact on child immunization in India: an application of the propensity score matching approach. Journal of Biosocial Science 2020:1-20.

6. de Graft-Johnson J, Kerber K, Tinker A, Otchere S, Narayanan I, Shoo R, Oluwole D, Lawn J: The maternal, newborn and child health continuum of care. Opportunities for Africa's Newborns 2006:23-36.

7. World Health Organization. Pulse survey on continuity of essential health services during the COVID19 pandemic: interim report, 27 August 2020. In.: World Health Organization; 2020. 
8. World Health Organization. Trends in maternal mortality: 1990-2015: estimates from WHO, UNICEF, UNFPA, World Bank Group and the United Nations Population Division: World Health Organization; 2015.

9. World Health Organisation. Trends in maternal mortality 2000 to 2017: estimates by WHO, UNICEF, UNFPA, World Bank Group and the United Nations Population Division. 2019.

10. Federal Ministry of Health. Health Sector Transformation Plan II. In.; 2020.

11. Ethiopian Central Statistical Agency (CSA) and ICF Rockville M. Ethiopia demographic and health survey. In.; 2016.

12. Emiru AA, Alene GD, Debelew GT: Women's retention on the continuum of maternal care pathway in west Gojjam zone, Ethiopia: multilevel analysis. BMC pregnancy and childbirth 2020, 20(1):1-14.

13. Tizazu MA, Sharew NT, Mamo T, Zeru AB, Asefa EY, Amare NS: Completing the Continuum of Maternity Care and Associated Factors in Debre Berhan Town, Amhara, Ethiopia, 2020. Journal of Multidisciplinary Healthcare 2021, 14:21.

14. Haile D, Kondale M, Andarge E, Tunje A, Fikadu T, Boti N: Level of completion along continuum of care for maternal and newborn health services and factors associated with it among women in Arba Minch Zuria woreda, Gamo zone, Southern Ethiopia: A community based cross-sectional study. Plos one 2020, 15(6): e0221670.

15. Asratie MH, Muche AA, Geremew AB: Completion of maternity continuum of care among women in the post-partum period: Magnitude and associated factors in the northwest, Ethiopia. PloS one 2020, 15(8):e0237980.

16. Shiferaw S, Spigt M, Godefrooij M, Melkamu Y, Tekie M: Why do women prefer home births in Ethiopia? BMC pregnancy and childbirth 2013, 13(1):1-10.

17. Tarekegn SM, Lieberman LS, Giedraitis V: Determinants of maternal health service utilization in Ethiopia: analysis of the 2011 Ethiopian Demographic and Health Survey. BMC pregnancy and childbirth 2014, 14(1):1-13.

18. Desa U: Transforming our world: The 2030 agenda for sustainable development. 2016.

19. Alkema L, Chou D, Hogan D, Zhang S, Moller A-B, Gemmill A, Fat DM, Boerma T, Temmerman M, Mathers C: Global, regional, and national levels and trends in maternal mortality between 1990 and 2015, with scenario-based projections to 2030: a systematic analysis by the UN Maternal Mortality Estimation Inter-Agency Group. The Lancet 2016, 387(10017):462-474.

20. Roberton T, Carter ED, Chou VB, Stegmuller AR, Jackson BD, Tam Y, Sawadogo-Lewis T, Walker N: Early estimates of the indirect effects of the COVID-19 pandemic on maternal and child mortality in low-income and middle-income countries: a modelling study. The Lancet Global Health 2020, 8(7):e901-e908.

21. Ashish K, Gurung R, Kinney MV, Sunny AK, Moinuddin M, Basnet O, Paudel P, Bhattarai P, Subedi K, Shrestha MP: Effect of the COVID-19 pandemic response on intrapartum care, stillbirth, and neonatal mortality outcomes in Nepal: a prospective observational study. The Lancet Global Health 2020, 8(10):e1273-e1281. 
22. Workicho A, Kershaw MJ, Berhanu L, Kebede M, Kennedy E: Essential Health and Nutrition Service Provision during the COVID-19 Pandemic: Lessons from Select Ethiopian Woredas. Current Developments in Nutrition 2021, 5(4).

23. Central Statistical Agency. Population Projections for Ethiopia 2007-2037. In.: Federal Democratic Republic of Ethiopia, Population Census Commission Addis ...

24. Ethiopia MoH: HEALTH SECTOR TRANSFORMATION PLAN I:HEALTH AND HEALTH RELATED INDICATORS. In.; 2019/2020.

25. Babure ZK, Jiru FA, Weldemarium TD: Client satisfaction among private wing and regular health care services at Nekemte referral hospital, east Wollega zone, Oromia regional state, Western Ethiopia: a comparative cross-sectional study, 2016. Journal of Public Health and Epidemiology 2018, 10(2):43-61.

26. Muluneh AG, Kassa GM, Alemayehu GA, Merid MW: High dropout rate from maternity continuum of care after antenatal care booking and its associated factors among reproductive age women in Ethiopia, Evidence from Demographic and Health Survey 2016. PloS one 2020, 15(6):e0234741.

27. Atnafu A, Kebede A, Misganaw B, Teshome DF, Biks GA, Demissie GD, Wolde HF, Gelaye KA, Yitayal $M$, Ayele TA et al: Determinants of the Continuum of Maternal Healthcare Services in Northwest Ethiopia: Findings from the Primary Health Care Project. J Pregnancy 2020, 2020:4318197.

28. Oh J, Moon J, Choi JW, Kim K: Factors associated with the continuum of care for maternal, newborn and child health in The Gambia: a cross-sectional study using Demographic and Health Survey 2013. BMJ open 2020, 10(11):e036516.

29. Kassie BA, Adane A, Tilahun YT, Kassahun EA, Ayele AS, Belew AK: Knowledge and attitude towards COVID-19 and associated factors among health care providers in Northwest Ethiopia. PloS one 2020, 15(8):e0238415.

30. Kassie BA, Asratie MH, Abate AT: The Effects of Fear and Knowledge of COVID-19 on Preventive Practice Among Pregnant Women Who Attend Antenatal Care in Northwest Ethiopia, 2020: Institution-Based Cross-Sectional Study. International Journal of Women's Health 2021, 13:95.

31. Mechessa DF, Ejeta F, Abebe L, Henok A, Nigussie T, Kebede O, Mamo Y: Community's Knowledge of COVID-19 and Its Associated Factors in Mizan-Aman Town, Southwest Ethiopia, 2020. International Journal of General Medicine 2020, 13:507.

32. Gebretsadik D, Gebremichael S, Belete MA: Knowledge, Attitude and Practice Toward COVID-19 Pandemic Among Population Visiting Dessie Health Center for COVID-19 Screening, Northeast Ethiopia. Infection and Drug Resistance 2021, 14:905.

33. Tadesse E: Antenatal Care Service Utilization of Pregnant Women Attending Antenatal Care in Public Hospitals During the COVID-19 Pandemic Period. International journal of women's health 2020, $12: 1181$.

34. Pant S, Koirala S, Subedi M: Access to maternal health services during COVID-19. Europasian Journal of Medical Sciences 2020, 2(2):48-52. 
35. Oluoch-Aridi J, Chelagat T, Nyikuri MM, Onyango J, Guzman D, Makanga C, Miller-Graff L, Dowd R: COVID-19 Effect on access to maternal health services in Kenya. Frontiers in Global Women's Health 2020, 1:19.

36. Jafree SR, Momina A, Muazzam A, Wajid R, Calib G: Factors Affecting Delivery Health Service Satisfaction of Women and Fear of COVID - 19: Implications for Maternal and Child Health in Pakistan. Maternal and child health journal 2021, 25(6):881-891.

37. Shapira G, Ahmed T, Drouard SHP, Amor Fernandez P, Kandpal E, Nzelu C, Wesseh CS, Mohamud NA, Smart F, Mwansambo $\mathrm{C}$ et al: Disruptions in maternal and child health service utilization during COVID-19: analysis from eight sub-Saharan African countries. Health Policy and Planning 2021.

38. Hailemariam S, Agegnehu W, Derese M: Exploring COVID-19 Related Factors Influencing Antenatal Care Services Uptake: A Qualitative Study among Women in a Rural Community in Southwest Ethiopia. Journal of Primary Care \& Community Health 2021, 12:2150132721996892.

39. Kikuchi K, Yasuoka J, Nanishi K, Ahmed A, Nohara Y, Nishikitani M, Yokota F, Mizutani T, Nakashima $\mathrm{N}$ : Postnatal care could be the key to improving the continuum of care in maternal and child health in Ratanakiri, Cambodia. PloS one 2018, 13(6):e0198829.

40. Sakuma S, Yasuoka J, Phongluxa K, Jimba M: Determinants of continuum of care for maternal, newborn, and child health services in rural Khammouane, Lao PDR. PloS one 2019, 14(4):e0215635.

41. Khan MN, Harris ML, Loxton D: Assessing the effect of pregnancy intention at conception on the continuum of care in maternal healthcare services use in Bangladesh: Evidence from a nationally representative cross-sectional survey. PloS one 2020, 15(11):e0242729.

42. Yeji F, Shibanuma A, Oduro A, Debpuur C, Kikuchi K, Owusu-Agei S, Gyapong M, Okawa S, Ansah E, Asare GQ et al: Continuum of Care in a Maternal, Newborn and Child Health Program in Ghana: Low Completion Rate and Multiple Obstacle Factors. PLoS One 2015, 10(12):e0142849.

43. Chaka EE, Parsaeian M, Majdzadeh R: Factors Associated with the Completion of the Continuum of Care for Maternal, Newborn, and Child Health Services in Ethiopia. Multilevel Model Analysis. International journal of preventive medicine 2019, 10:136.

44. Maheen $\mathrm{H}$, Hoban E, Bennett C: Factors affecting rural women's utilisation of continuum of care services in remote or isolated villages or Pakistan-A mixed-methods study. Women and Birth 2021, 34(3):257-265.

45. Chalise B, Chalise M, Bista B, Pandey AR, Thapa S: Correlates of continuum of maternal health services among Nepalese women: Evidence from Nepal Multiple Indicator Cluster Survey. PLoS One 2019, 14(4):e0215613.

46. Shitie A, Assefa N, Dhressa M, Dilnessa T: Completion and Factors Associated with Maternity Continuum of Care among Mothers Who Gave Birth in the Last One Year in Enemay District, Northwest Ethiopia. Journal of Pregnancy 2020, 2020.

47. Wang W, Hong R: Completing the Continuum of Care for Maternal and Newborn Heath in Cambodia: Who Drops Out?: ICF International; 2013. 
48. Amare NS, Araya BM, Asaye MM: Dropout from maternity continuum of care and associated factors among women in Debre Markos town, Northwest Ethiopia. bioRxiv 2019:620120.

49. Shudura E, Yoseph A, Tamiso A: Utilization and Predictors of Maternal Health Care Services among Women of Reproductive Age in Hawassa University Health and Demographic Surveillance System Site, South Ethiopia: A Cross-Sectional Study. Advances in Public Health 2020, 2020:5865928.

50. Wado YD, Afework MF, Hindin MJ: Unintended pregnancies and the use of maternal health services in Southwestern Ethiopia. BMC international health and human rights 2013, 13:36.

51. Limenih MA, Endale ZM, Dachew BA: Postnatal care service utilization and associated factors among women who gave birth in the last 12 months prior to the study in Debre Markos town, northwestern Ethiopia: a community-based cross-sectional study. International journal of reproductive medicine 2016, 2016.

52. Tiruneh GT, Worku A, Berhane Y, Betemariam W, Demissie M: Determinants of postnatal care utilization in Ethiopia: a multilevel analysis. BMC pregnancy and childbirth 2020, 20(1):1-12.

53. Adams YJ, Smith BA: Integrative review of factors that affect the use of postpartum care services in developing countries. Journal of Obstetric, Gynecologic \& Neonatal Nursing 2018, 47(3):371-384.

54. Kazanga I, Munthali AC, McVeigh J, Mannan H, MacLachlan M: Predictors of utilisation of skilled maternal healthcare in Lilongwe district, Malawi. International journal of health policy and management 2019, 8(12):700.

55. Asres A, Davey G: Factors associated with safe delivery service utilization among women in Sheka Zone, Southwest Ethiopia. Maternal and child health journal 2015, 19(4):859-867.

56. Belda SS, Gebremariam MB: Birth preparedness, complication readiness and other determinants of place of delivery among mothers in Goba District, Bale Zone, South East Ethiopia. BMC pregnancy and childbirth 2016, 16(1):1-12.

57. Berhe A, Bayray A, Berhe Y, Teklu A, Desta A, Araya T, Zielinski R, Roosevelt L: Determinants of postnatal care utilization in Tigray, Northern Ethiopia: A community based cross-sectional study. PLoS One 2019, 14(8):e0221161.

58. Nawal D, Goli S: Birth preparedness and its effect on place of delivery and post-natal check-ups in Nepal. PloS one 2013, 8(5):e60957.

59. Hordofa MA, Almaw SS, Berhanu MG, Lemiso HB: Postnatal care service utilization and associated factors among women in Dembecha District, Northwest Ethiopia. Sci J Public Health 2015, 3(5):686692.

60. Khanal V, Adhikari M, Karkee R, Gavidia T: Factors associated with the utilisation of postnatal care services among the mothers of Nepal: analysis of Nepal demographic and health survey 2011. BMC women's health 2014, 14(1):1-13.

61. Enos JY, Amoako RD, Doku IK: Utilization, Predictors and Gaps in the Continuum of Care for Maternal and Newborn Health in Ghana. International Journal of Maternal and Child Health and AIDS 2021, 10(1):98. 


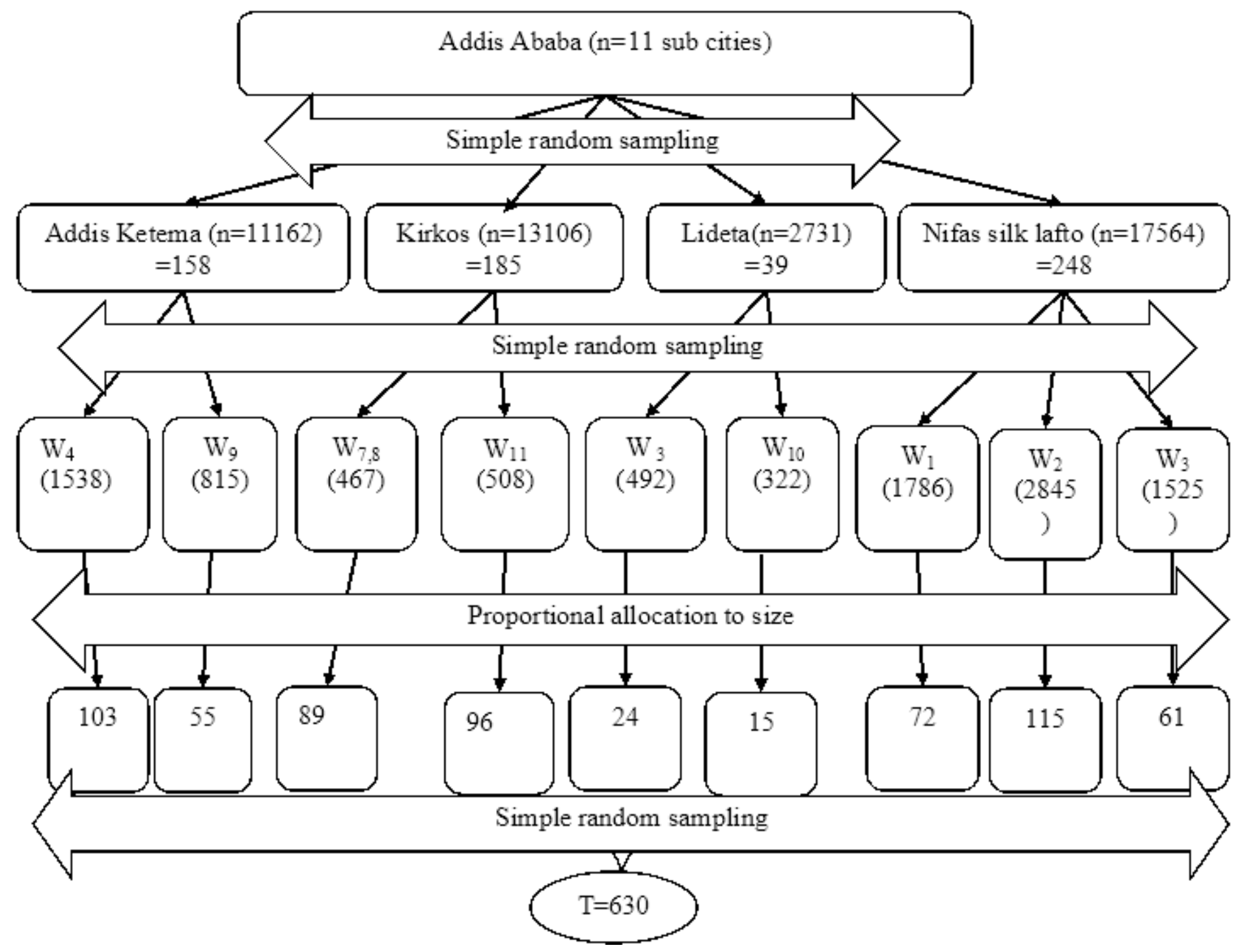

Figure 1

Schematic presentation of the sampling procedure for the study conducted among women who gave birth in the last two years in Addis Ababa, Ethiopia, $2021 \mathrm{Key}$ : W=Wereda, T=Total 


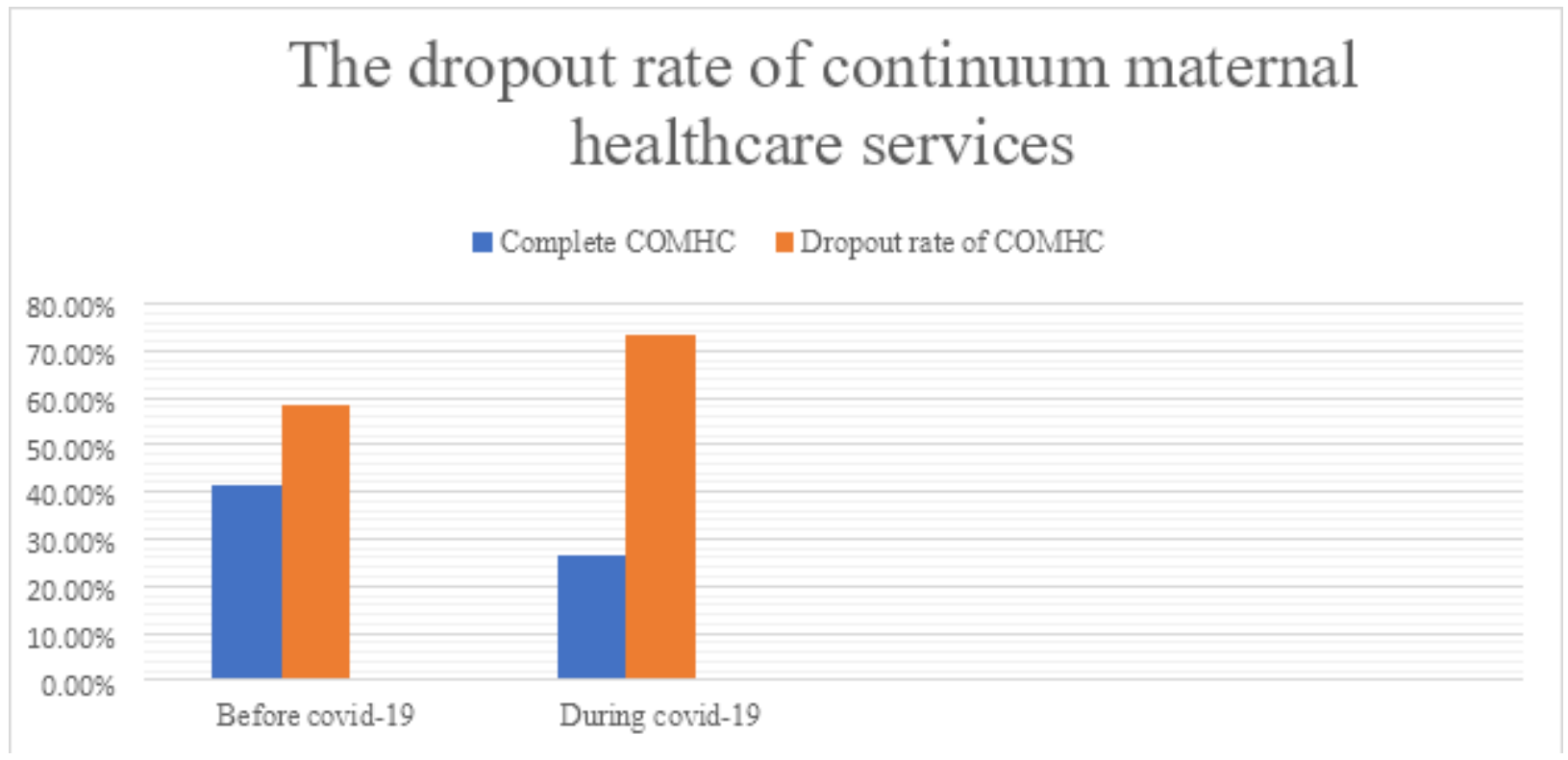

Figure 2

The dropout rate of a continuum of maternal Health care before and during the COVID-19 pandemic among women who gave birth in the last two years in Addis Ababa,2021 $(n=585)$ 